\title{
Analysis Of The Genotypic Profile And Its Relationship With The Clinical Manifestations In People With Cystic Fibrosis: Study From A Registry Of Rare Diseases.
}

\author{
Senay Rueda Nieto ( $\square$ s.ruedanieto@um.es ) \\ Murcia Health Service: Servicio Murciano de Salud https://orcid.org/0000-0002-3692-8148 \\ Pedro Mondejar-Lopez \\ Virgen de la Arrixaca University Hospital: Hospital Clinico Universitario Virgen de la Arrixaca \\ María-Pilar Mira-Escolano \\ Murcia Health Service: Servicio Murciano de Salud \\ Ana Cutillas-Tolín \\ University of Murcia: Universidad de Murcia \\ Luis Alberto Maceda-Roldán \\ Murcia Health Service: Servicio Murciano de Salud \\ Julián Jesús Arense-Gonzalo \\ University of Murcia: Universidad de Murcia \\ Joaquín A. Palomar-Rodríguez \\ Murcia Health Service: Servicio Murciano de Salud
}

\section{Research Article}

Keywords: Cystic fibrosis, CFTR, Genotype, Phenotype, Rare Disease, Registry.

Posted Date: February 25th, 2022

DOl: https://doi.org/10.21203/rs.3.rs-1214672/v1

License: @ (i) This work is licensed under a Creative Commons Attribution 4.0 International License. Read Full License 


\section{Abstract}

Background: Cystic fibrosis (CF) has a very heterogeneous mutational spectrum in Europe. This variability has also been described in Spain, and there are numerous studies that relate CFTR variants with the symptoms of the disease. Most of them analyze determinate clinical manifestations or specific sequence variants in patients from clinical units. Others use registry data without addressing the genotype-phenotype relationship. Therefore, the objective of this study is to describe the genetic and clinical characteristics of people with $\mathrm{CF}$, and to analyze the relationship between both, using data from the rare diseases registry of a region in southeastern Spain.

Methods: A cross-sectional study was carried out in people with a confirmed diagnosis of CF registered in the Rare Diseases Information System (SIER) of the Region of Murcia (Spain). The patients were classified into two genotypes according to the functional consequence that the genetic variants had on the CFTR protein.

Results: There were 192 people diagnosed with CF reported in the Region of Murcia until December 31, 2018. Seventy-six different variants were described being the most common c.1521_1523delCTT (p.Phe508del) in 58.3\% of people and $37.0 \%$ of alleles. Sixtyseven percent of the patients were classified as high-risk genotype, which was associated with a lower percentage of FEV ${ }_{1}$ [OR: 3.4 $(95 \% \mathrm{Cl}: 1.1,10.8)$ ], an increased risk of colonization by Pseudomonas aeruginosa and Achromobacter xylosoxidans [0R: 4.2 (95\%Cl: $1.3,13.8)$ and $7.1(95 \% \mathrm{Cl}: 1.1,47.2)$, respectively] and the presence of pancreatic insufficiency [OR: $21.8(95 \% \mathrm{Cl}: 7.9,59.9)]$ as compared with those with mild variants.

Conclusions: The Region of Murcia has one of the lowest allele frequencies of p.Phe508del described in Europe and high genetic heterogeneity, which could explain the high proportion of patients with mild disease. Furthermore, our results support the association between genotypes compound of two severe variants and the presence of pancreatic insufficiency, increased risk of respiratory infection, and serious lung damage.

\section{Background}

Cystic fibrosis (CF) (ORPHA: 586; OMIM: 219700) is the rare genetic disease, of autosomal recessive inheritance, most common in the Caucasian population ${ }^{1}$.

This disorder has its origin in anomalies in the sequence of the CF transmembrane conductance regulator gene (CFTR) (OMIM 602421), which causes an alteration in the chloride and bicarbonate transport channel regulated by cyclic adenosine monophosphate (cAMP). These alteration results in the appearance of various multisystemic clinical manifestations that generate a progressive deterioration of the patients ${ }^{2,3}$.

Since the CFTR gene was described in $1989^{4-6}, 2,107$ variants have been reported in the cystic fibrosis mutation database ${ }^{7}$, of which only 431 are associated with risk of disease ${ }^{8}$. The most common is c.1521_1523delCTT (p.Phe508del), present in more than $80 \%$ of alleles in the world population with CF, and whose frequency is higher in northern European countries. In certain populations, other variants can reach higher frequencies than p.Phe508del and some of them have only been described in specific territories ${ }^{9-11}$.

Although p.Phe508del is also the most common in Spain, it is less common than in other northern European countries. Likewise, notable differences have been described between the different regions of the country in the frequency of this sequence alteration, as well as a great heterogeneity in the rest of the CFTR changes ${ }^{12,13}$.

The sequence variants are classified into 7 classes $^{14}$ according to the effect they have on the amount, function or stability of CFTR in the cell membrane ${ }^{15,16}$. Recent studies have considered classifying sequence alterations into 2 groups; minimal function variants (I, II, $\mathrm{III}$ and $\mathrm{VII}$ ), that are considered high risk mutation and are associated with a more severe phenotype and early deterioration, and residual function or low risk mutations (IV, V and VI) that can preserve part of CFTR function and lead to milder late-onset disease ${ }^{17,18}$. However, it should be remembered that the variability or severity of CF symptoms also seems to be explained by factors such as age, disease progression, different environmental factors, and modifying genes ${ }^{19-21}$.

In addition, nowadays, several studies have described an association between the genotype and the different clinical manifestations, mainly reproductive, pancreatic and other gastrointestinal disorders, using different ways of classifying the genotype $22-25$. 
In Spain, different studies have been carried out on the genotype-phenotype relationship of patients followed up in CF units, although all include specific clinical manifestations or particular sequence variants ${ }^{26,27}$. Studies have also been carried out from patient registries, however, none of them have addressed the study of the relationship between genotype and phenotype so far ${ }^{13,28,29}$.

Recently, rare diseases registries have been positioned as a fundamental instrument since they allow a greater knowledge of the epidemiology and characteristics of the registered patients ${ }^{30,31}$. The Region of Murcia has a Rare Diseases Information System (SIER), which, starting from different sources of information, captures people with any of these diseases and provides different types of information about each of them. For this reason, the objective of this study was to describe the clinical and genetic characteristics, as well as to analyze the relationship between the genotype and the different manifestations of people with CF based on information from the Rare Diseases Registry of a region of southeastern Spain.

\section{Methods}

Study population

A cross-sectional study was carried out from people with a confirmed diagnosis of CF registered in the Rare Diseases Information System of Murcia (SIER) ${ }^{32}$, whose disease had been detected until December 31, 2018. People with CFTR related disorders (CFTR-RDs), CF-screen positive inconclusive diagnosis (CF-SPID) and healthy carriers were excluded. The informed consent of the study population was not required as the SIER is subject to the personal data protection regulations and registered in the Spanish Data Protection Agency ( $n^{\circ} 2101040243$ of April 14, 2010) ${ }^{33}$. Even so, the study was presented to the Clinical Research Ethics Committee of the International Doctoral School of the University of Murcia ( $\left.n^{\circ} 3376 / 2021\right)$ and it was approved on May 6, 2021.

Rare Diseases Information System (SIER)

The SIER, existing since 2010, is a population registry of rare diseases (RDR) of the Region of Murcia, an Autonomous Community located in southeastern Spain with an estimated population of 1,493,898 inhabitants as of January 1, 2019, which constitutes $3.18 \%$ of the Spanish population. For the inclusion of people with some rare disease (RD), this system uses a list of selected codes from the International Classification of Diseases (ICD) and integrates information from different sources. Currently, the SIER has 47 different sources of information; administrative clinics such as the regional Minimum Basic Data Set (MBDS), pre-existing patient registries such as the renal disease registry, orphan or foreign drug dispensing database, databases of people with recognition of disability and dependency, notification of patient associations, or Clinical Hospital Units. For this study, the Regional CF Unit of the Virgen de la Arrixaca University Clinic Hospital (HCUVA) was the main source of information in the contribution of people with CF to the registry. The sources that incorporated some patients of the study are shown in Table 1.

Once possible cases of RD have been incorporated into the registry they undergo a validation process, confirming the evidence of the diagnosis once the electronic medical record of the patient has been reviewed ${ }^{32}$.

Regarding the codes for the detection of people with CF, the 277.0 [0-9] in its ninth revision, Clinical Modification of International Classification of Diseases (ICD-9-CM) was used until 2015, and the code E84 [0-9] in the tenth version of the Spanish Clinical Modification (ICD-10-ES) from 2016 to 2018.

Data collection

The data collected from each patient included:

Consultation of basic patient information: sex, age at diagnosis (<18 years or $\geq 18$ years), age on December 31 st, 2018 , native country of parents, diagnosis by neonatal screening, death and transplant (yes/no).

Obtaining genetic information: Firstly, information was obtained about the variants of the CFTR gene. In addition, the project database CFTR2 $^{8}$, Database of single nucleotide polymorphisms (dbSNP) ${ }^{34}$, Database of cystic fibrosis mutations ${ }^{7}$ and ClinVAr $^{35}$ were $^{2}$ consulted to include the type of alteration that patients presented in the gene sequence, along with the associated nucleotide change, amino acid change and its molecular and clinical consequence. Secondly, the patients were classified into 2 groups according to genotype; "high-risk" if there were 2 mutations of minimal function or class I, II, III, and VII and "low-risk" if at least one allele carried a residual mutation or class IV, V and VI, with some exceptions ${ }^{1,17,18}$. 
Procurement of clinical manifestations: We collected up to December 31, 2018, the following clinical manifestations: respiratory and digestive symptoms, metabolic disturbances and others like bone alterations.

Respiratory symptoms: Evidence of at least one episode of Allergic Bronchopulmonary Aspergillosis (ABPA), one or more clinically relevant episodes of hemoptysis (> $200 \mathrm{ml}$ ), presence of nasal polyps, chronic respiratory colonizations by different microorganisms (Staphylococcus aureus, Burkholderia cepacia or Pseudomonas aeruginosa) and at least one documented acute infection with methicillin-resistant Staphylococcus aureus, Achromobacter xylosoxidans, or nontuberculous mycobacteria.

Lung function was evaluated using the best value of the forced expiratory volume in the first second $\left(\mathrm{FEV}_{1}\right)$ recorded in 2018, normalized with respect to its theoretical using the Global Lung Function Initiative (GLI) tool and expressed as a percentage of the predicted value. The variable was dichotomized into $\leq 90 \%$ and $>90 \%$, the cut-off point used in other studies ${ }^{36}$.

Digestive symptoms: presence of meconium ileus at birth, rectal prolapse, intussusception, distal intestinal obstruction syndrome (DIOS), pancreatic insufficiency, recurrent acute or chronic pancreatitis and CF-related liver disease (cirrhosis or liver disease with or without cirrhosis, including fatty liver).

Metabolic disturbances: insulin-dependent CF-related diabetes (CFRD) and at least one CF-related episode of dehydration requiring medical attention.

Others: bone disorders including low bone density, osteoporosis, and digital arthropathy.

For this work, the CF diagnosis of the studied population was contrasted with the responsible physician for the CF Regional Unit. In addition, the doctor provided the necessary information to collate and complete the different clinical manifestations and the genetic information of each of the people included.

Statistical analysis

We described the clinical and demographic variables in the two groups of genotypes established by hypothesis contrast test according to the type of variables and their normality. The normality test was carried out using the Kolmogorov-Smirnov test. The absolute and relative frequencies of the clinical and demographic variables were described. The allelic frequency of the CFTR gene variants in the studied population was also presented.

For the quantitative variables, Student's $t$-test was used if they were normally distributed and Mann Whitney's U-test if they were not. For qualitative variables, Chi-squared ${ }^{2}$ or Fisher test was used when applied.

Additionally, crude and adjusted odds (OR) and $95 \%$ confidence intervals $(95 \% \mathrm{Cl})$ were calculated using binary logistic regression analysis to examine associations between genotype and clinical manifestations of the participants. There was a significant statistically association between genotype and age at diagnosis and as of December 31, $2018(P<0.01)$. Therefore, these variables were taken into account for the adjustment of the model.

In addition, a sensitivity analysis was performed to verify that the patients diagnosed by neonatal screening did not lead to biased.

All tests were two-tailed and the level of statistical significance was established at $\leq 0.05$. Statistical analyzes were performed with the IBM SPSS 25.0 statistical package (IBM Corporation, Armonk, New York, USA).

\section{Results}

There were 192 people diagnosed with CF registered in SIER until December 31, 2018. Those cases not compatible with the clinical entity of CF were excluded.

For the total number of people in the study, fifty-three-point six percent were male whose mean age was $20.0 \pm 15.2$ years [median 15.0, interquartile range (IQR) 7.0-31.0] and 46.4\% female (mean $24.5 \pm 16.2$ years, median 23.0 and IQR 10.0-35.0). Adults (18 years or older) were $41.7 \%$ of all patients. The mean age at diagnosis was $7.8 \pm 14.4$ years and the median 0.0 years (IQR 0.0-7.5). Sixteen-point one percent of people $(n=31)$ were diagnosed by the neonatal screening program, which was implemented in Murcia in March 2007. 
In $84.9 \%$ of the study population, the native country of parents was Spain. In descending order of frequency parents had others nationalities: Ecuadorians (6.2\%), English (2.6\%), Moroccans (2.1\%), Argentines (1.0\%). In the remaining 3.2\%, the parents were: French, Peruvians, Moldovans, Ukrainians, Hungarians and Bulgarians.

As a result of the clinical manifestations, respiratory problems were present in $63.0 \%$ of the patients. The mean $\mathrm{FEV}_{1}$ percentage was $90.0 \pm 21.4$ and was inversely correlated with the age of the patients $(-0.36 ; \mathrm{P}<0.01)$. On the other hand, $57.8 \%$ of the people presented infection / colonization by some bacterial pathogen at some point. The most frequently isolated microorganism was Staphylococcus aureus, with those under 18 years of age being the most likely to be infected by this germ. Among digestive manifestations, pancreatic insufficiency was the most common (56.8\%). Furthermore, $8.9 \%$ presented meconium ileus as the first manifestation of the disease.

Table 2 shows the main demographic and clinical characteristics of the patients according to their genotype, available in $94.8 \%$ of the cases $(n=182)$. Sixty-seven percent of the patients were classified as high-risk $(n=122)$ genotype and thirty-three percent as low-risk genotype $(n=60)$.

People with a high-risk genotype were younger as of December 31, $2018(\mathrm{p}<0.001)$, with a lower mean age at diagnosis $(p<0.001)$, and lower mean $\mathrm{FEV}_{1}$ values $(\mathrm{p}=0.045)$ with respect to the low-risk genotype. Likewise, the high-risk genotype presented a higher frequency of respiratory infections by methicillin-resistant Staphylococcus aureus and Achromobacter xylosoxidans $(p=0.034)$. Furthermore, a higher incidence of meconium ileus, pancreatic insufficiency, CF-related liver disease and CFRD was observed in those patients $(\mathrm{p} \leq 0.01)$. On other hand, $15.6 \%$ of patients with a high-risk genotype required lung or liver transplant compared to $6.7 \%$ with a low-risk genotype, although without significant differences $(p=0.089)$.

Table 3 shows the frequency of the CFTR gene variants by alleles in the 192 patients studied. The most common mutation was p.Phe 508 del in $58.3 \%$ of people $(27.0 \%$ homozygous and $73.0 \%$ heterozygous) and $37.0 \%$ of alleles.

Seventy-six different variants were detected, and around $50 \%$ of all alleles, 3 types of mutations were found: p.Phe508del, c.1624G> T (p.Gly542Ter) and c.3017C> A (p.Ala1006Glu). Other variants were observed in 1.6\% to $3.9 \%$ of alleles, usually in compound heterozygosity with other residual function mutations or with p.Phe508del. The rest of the variants appeared at frequencies equal to or less than $1 \%$.

Table 4 shows the multivariate analysis of the relationship between genotype and clinical manifestations. High-risk genotype was significantly associated with a lower percentage of $\mathrm{FEV}_{1}$ value [OR:3.4 $\left.(95 \% \mathrm{Cl}: 1.1,10.8)\right]$ a higher risk of developing Pseudomonas aeruginosa and Achromobacter xylosoxidans infection [OR: $4.2(95 \% \mathrm{Cl}: 1.3,13.8)$ and $7.1(95 \% \mathrm{Cl}: 1.1,47.2)$, respectively] $(\mathrm{P}<0.05)$, and the presence of pancreatic insufficiency [OR: $21.8(95 \% \mathrm{Cl}: 7.9,59.9)](\mathrm{P}<0.001)$ compared to low-risk genotype. In the sensitivity analysis, similar associations were obtained when both groups were analyzed separately. No other associations were observed with the different clinical manifestations.

\section{Discussion}

The present study shows the CFTR sequence alterations and their relationship with the clinical manifestations of people with CF included in the rare diseases registry of Region of Murcia. Although the mutational spectrum of CFTR in Region of Murcia was published in $2009^{37}$, our study improves the information available since we do not have evidence of other regional or national articles that analyze the genotype-phenotype relationship in patients registered in this type of registry.

On the other hand, the most frequently observed variants in the study population are p.Phe508del, p.Gly542Ter. and p.Ala1006Glu. However, up to 76 different variants have been detected, supporting the great heterogeneity described in Mediterranean countries ${ }^{9,38}$.

The p.Phe508del is the most common sequence change in 58.3\% of people, a figure lower than that reported by other Spanish Autonomous Communities ${ }^{39,40}$ and different European Mediterranean countries ${ }^{1,11,41-43}$. In addition, its frequency by alleles is among the lowest data described to date (37.0\%), due in large part to the high percentage of carriers of the variant in heterozygosity (73\%) compared to the $48.1 \%$ reported recently for the registry of CF Patients in Spain ${ }^{13}$.

Moreover, Region of Murcia constitutes, together with Andalusia and the Balearic Islands, one of the Spanish Autonomous Communities with the highest percentage of alleles with the variant p.Gly542Ter ${ }^{40,44}$. In fact, according to the study by Estivill et al. ${ }^{12}$ this alteration is more common in Mediterranean countries with an average frequency of $6.1 \%$ and the highest prevalence described so 
far in the Balearic Islands (16.7\%). Recent data from the Spanish CF registry suggest that $7.7 \%$ of registered patients carry it ${ }^{13}$. In SIER, this variant is present in $16.5 \%$ of patients and $8.1 \%$ of CFTR alleles.

The variants described above are followed in frequency by p.Ala1006Glu and c.617T>G (p.Leu206Trp), rare in the rest of European countries $^{11,13}$. However, other frequent mutations in Europe such as c. $1652 \mathrm{G}>\mathrm{A}$ (p.Gly551Asp), which have a specific treatment ${ }^{45}$, have not been described in our study population.

On the other hand, to analyze the relationship between genetics and clinical characteristics, we grouped patients into 2 genotypes according to the consequence that the different variants have on the function and quantity of CFTR protein, as other studies have done ${ }^{17,46}$. Thirty-three percent of the people for whom information was available are classified as low-risk genotype. This represents a much higher percentage of patients with mild variants than that described by McKone ${ }^{17}$ or De Boeck ${ }^{46}$ in some European countries. However, other authors such as De Gracia point out that the mild forms could be more frequent than has been described so far ${ }^{47}$.

The frequency of a high percentage of people with a low-risk genotype can largely explain the presence of the different clinical manifestations. An example of this is pancreatic insufficiency, which exists in $67.7 \%$ of the patients in this study. Although it has been classically described that approximately $85-90 \%$ of CF cases are associated with pancreatic insufficiency, our results show that this percentage may be compatible with severe forms, since pancreatic insufficiency is present in $89.2 \%$ of our cases classified as high-risk versus $30.5 \%$ as low-risk.

In the study population, the high-risk genotype is associated with a younger age and an earlier diagnosis, a relationship already reported by several studies ${ }^{10,48}$. Therefore, we consider it necessary to adjust the multivariate model for these variables.

Our results are compatible with previous studies that have described an association between genotype and respiratory and digestive symptoms in people with CF. In our study population, the most consistent findings are observed for the appearance of pancreatic insufficiency with a high-risk genotype, but also for a lower percentage of predicted $\mathrm{FEV}_{1}$ and colonization by Pseudomonas aeruginosa and Achromobacter xylosoxidans.

The relationship between CFTR dysfunction and pancreatic damage, has already been reported using various ways of classifying the genotype, associating a greater risk of presenting pancreatic insufficiency in those with 2 copies of severe sequence variants ${ }^{49-52}$.

Regarding colonization by microorganisms, Somayaji et al. ${ }^{53}$ and Marsac et al. ${ }^{54}$ have shown that proteobacteria such as Achromobacter xylosoxidans have a tendency to appear in highly inflamed areas that are often coinfected with Pseudomonas in CF populations that present greater lung damage and associate minimal functional mutations.

Other studies have shown an association between the rest of the microorganisms and the greater loss of function of CFTR ${ }^{55}$. This can be caused by the reduction of ion transport that leads to dehydration of the lung surface, causing repeated bacterial superinfections that generate a pro-inflammatory state and, therefore, new infections by different pathogens. However, no statistically significant associations have been found in this work. The same occurs with complications such as CFRD and CF-related liver disease, in which no significant association was observed in the adjusted model.

Bearing in mind the limitations of the study, although our population was relatively small, the cases included came from a RD registry, which is a very useful tool to approximate the reality of the spectrum of CF and other RD in our geographical area. In any case, a small sample size would be relevant for a type II error but not in our study, since statistically significant associations were found. On the contrary, we cannot rule out that type II error may explain the non-significant findings of other clinical manifestations in relation to the genotype.

On the other hand, not all clinical information was available for all patients. However, there were no significant differences in participant characteristics, such as genotype or age, between those with this information and those without, so information bias is unlikely.

In addition, the possibility that the neonatal screening diagnosis could act as a modifier of the association between clinical manifestations and genotype is considered, constituting a limitation of our study. However, we carried out a sensitivity analysis and verified that the associations are similar when analyzing both groups separately, so it is concluded that there is no modification of the effect by screening. 
Finally, it should be noted that not all the people with CF in the study had the same time of evolution of the disease. In fact, certain conditions such as pancreatic insufficiency are described as being closely related to age. However, a significant association was obtained for this relationship in the studied population when we adjust the model for age and age at diagnosis.

\section{Conclusions}

To our knowledge, this is the first study that addresses the association between the genotype and the clinical manifestations associated with CF in patients included in a rare diseases registry, which provides us with a complete vision of the disease for all the people in our geographical area. In Region of Murcia there is a great genetic heterogeneity, which is demonstrated in the different sequence variants described in the study. Furthermore, the frequency that we present in relation to $p$.Phe508del is one of the lowest described in Spain and Europe. For this reason, the percentage of people classified as a low-risk genotype was higher than that described by other authors, which determines a lower frequency of appearance of certain clinical alterations like pancreatic insufficiency. In addition, high-risk genotype of CF increased the risk of severe lung damage, pancreatic insufficiency and chronic respiratory colonization by certain microorganisms respect to low-risk genotype, according to some previous publications.

\section{List Of Abbreviations}

cAMP: cyclic Adenosine Monophosphate.

CF: Cystic Fibrosis.

CFRD: CF-Related Diabetes mellitus.

CF-SPID: Cystic Fibrosis Screen Positive Inconclusive Diagnosis.

CFTR: Cystic Fibrosis Transmembrane Conductance Regulator.

CFTR-RDs: Cystic Fibrosis Transmembrane Conductance Regulator Related Disorders.

Cl: Confidence Interval.

FEV1: Forced Expiratory Volume in the first second.

HCUVA: Virgen de la Arrixaca Universitary Clinic Hospital.

ICD: International Classification of Diseases.

IQR: Interquartile Range.

MRSA: Methicillin-resistant Staphylococcus aureus.

OR: Odds Ratio.

PI: Pancreatic Insufficiency.

PS: Pancreatic Sufficiency.

RD: Rare Disease.

RDR: Rare Disease Registry.

SIER: Rare Diseases Information System.

\section{Declarations}

Ethics approval and consent to participate: The informed consent of the study population was not required as the SIER is subject to the personal data protection regulations and registered with the Spanish Data Protection Agency ( $\mathrm{n}^{\circ} 2101040243$ of April 14, 
2010) 32 . Anyway, the study received ethical approval from Clinical Research Ethics Committee of the International Doctoral School of the University of Murcia. Ref. no 3376/2021, 6 May 2021.

Consent for publication: Not applicable.

\section{Availability of data and materials}

The pseudo-anonymized data set used to carry out this study and that support its findings are restricted following Regulation (EU) 2016/679, Law 3/2018 on the Protection of Personal Data, Law 14/2007 on Biomedical Research and the Law 37/2007. and Law $18 / 2015$ on the Reuse of Public Sector Information. By virtue of the foregoing, it is only possible to access the aggregated data with a reasonable request at the following address: serplan@listas.carm.es

Competing interests: The authors declared no conflicts of interest with respect to the authorship and/or publication of this article.

Funding: This article has not received funding from any organization or entity.

Contributions: SRN and MPME designed and initiated the current study. PML was responsible for collecting clinical and genetic manifestations data and follow-up of patients. MPME and JAPR coordinated the purification of the information and managed the SIER. LAMR clarified the genetic concepts and helped in their correct writing. SRN, MPME, ACT and JJAG were responsible for analizing data. MPME and SRN writed the draft version of manuscript. All authors commented on and approved the final manuscript.

\section{Acknowledgment}

We greatly appreciate the collaboration of all the sources that make up the SIER and the work carried out by the staff of the Planning and Health Financing Department in charge of its maintenance: Pilar Ciller Montoya, Fernando Cano Candela, Antonio Serrano Pinto, Antonia Sánchez Escámez, Juana María Cayuela Fuentes.

\section{References}

1. De Boeck K. Cystic fibrosis in the year 2020: A disease with a new face. Acta Paediatr. 2020;109(5):893-9.

2. Elborn JS. Cystic fibrosis. Lancet. 2016;388(10059):2519-31.

3. Brown SD, White R, Tobin P. Keep them breathing: Cystic fibrosis pathophysiology, diagnosis, and treatment. JAAPA. 2017;30(5):23-7.

4. Kerem B, Rommens JM, Buchanan JA, Markiewicz D, Cox TK, Chakravarti A, et al. Identification of the cystic fibrosis gene: genetic analysis. Science. 1989;245(4922):1073-80.

5. Riordan JR, Rommens JM, Kerem B, Alon N, Rozmahel R, Grzelczak Z, et al. Identification of the cystic fibrosis gene: cloning and characterization of complementary DNA. Science. 1989;245(4922):1066-73.

6. Rommens JM, lannuzzi MC, Kerem B, Drumm ML, Melmer G, Dean M, et al. Identification of the cystic fibrosis gene: chromosome walking and jumping. Science. 1989;245(4922):1059-65.

7. Cystic fibrosis mutation database [Internet]. Sickkids.on.ca. [citado el 16 de noviembre de 2021]. Disponible en: http://www.genet.sickkids.on.ca/.

8. Welcome to CFTR2 [Internet]. Cftr2.org. [citado el 16 de noviembre de 2021]. Disponible en: https://cftr2.org/.

9. Bobadilla JL, Macek M Jr, Fine JP, Farrell PM. Cystic fibrosis: a worldwide analysis of CFTR mutations-correlation with incidence data and application to screening. Hum Mutat. 2002;19(6):575-606.

10. Castellani C, Cuppens H, Macek M Jr, Cassiman JJ, Kerem E, Durie P, et al. Consensus on the use and interpretation of cystic fibrosis mutation analysis in clinical practice. J Cyst Fibros. 2008;7(3):179-96.

11. ECFSPR Annual Report 2018, Zolin A, Orenti A, Naehrlich L, Jung A, van Rens J, et al, 2020.

12. Estivill $X$, Bancells $C$, Ramos C. Geographic distribution and regional origin of 272 cystic fibrosis mutations in European populations. Hum Mutat. 1997;10(2):135-54.

13. Spanish Cystic Fibrosis Registry. Report 2018, Spanish Cystic Fibrosis Society Registry Group. July 2021.

14. De Boeck K, Amaral MD. Progress in therapies for cystic fibrosis. Lancet Respir Med. 2016;4(8):662-74. 
15. Bombieri C, Seia M, Castellani C. Genotypes and phenotypes in cystic fibrosis and cystic fibrosis transmembrane regulator-related disorders. Semin Respir Crit Care Med. 2015;36(2):180-93.

16. Sosnay PR, Raraigh KS, Gibson RL. Molecular genetics of cystic fibrosis transmembrane conductance regulator: Genotype and phenotype. Pediatr Clin North Am. 2016;63(4):585-98.

17. McKone EF, Goss CH, Aitken ML. CFTR genotype as a predictor of prognosis in cystic fibrosis. Chest. 2006;130(5):1441-7.

18. Halderman AA, Lee S, London NR, Day A, Jain R, Moore JA, et al. Impact of high- versus low-risk genotype on sinonasal radiographic disease in cystic fibrosis. Laryngoscope. 2019;129(4):788-93.

19. McGarry ME, Williams WA 2nd, McColley SA. The demographics of adverse outcomes in cystic fibrosis. Pediatr Pulmonol. 2019;54(Suppl 3(S3):74-83.

20. Cutting GR. Modifier genes in Mendelian disorders: the example of cystic fibrosis: Modifiers of cystic fibrosis. Ann N Y Acad Sci. 2010;1214(1):57-69.

21. Collaco JM, Cutting GR. Update on gene modifiers in cystic fibrosis. Curr Opin Pulm Med. 2008;14(6):559-66.

22. Ooi CY, Dorfman R, Cipolli M, Gonska T, Castellani C, Keenan K, et al. Type of CFTR mutation determines risk of pancreatitis in patients with cystic fibrosis. Gastroenterology. 2011;140(1):153-61.

23. Zielenski J. Genotype and phenotype in cystic fibrosis. Respiration. 2000;67(2):117-33.

24. Kerem E, Corey M, Kerem BS, Rommens J, Markiewicz D, Levison H, et al. The relation between genotype and phenotype in cystic fibrosis-analysis of the most common mutation (delta F508). N Engl J Med. 1990;323(22):1517-22.

25. Cystic Fibrosis Genotype-Phenotype Consortium. Correlation between genotype and phenotype in patients with cystic fibrosis. N Engl J Med. 1993;329(18):1308-13.

26. García Hernández G, Antelo C, Maiz L, María Girón R, Salcedo A, Martínez Gimeno A, et al. Pacientes con fibrosis quística atendidos en las unidades de fibrosis quística de la Comunidad de Madrid: estudio transversal de 387 casos. Med Clin (Barc). 2004;122(18):698-700.

27. Casals T, Bassas L, Egozcue S, Ramos MD, Giménez J, Segura A, et al. Heterogeneity for mutations in the CFTR gene and clinical correlations in patients with congenital absence of the vas deferens. Hum Reprod. 2000;15(7):1476-83.

28. Olveira C, Padilla A, Martínez-García M-Á, de la Rosa D, Girón R-M, Vendrell M, et al. Etiología de las bronquiectasias en una cohorte de 2.047 pacientes. Análisis del registro histórico español. Arch Bronconeumol. 2017;53(7):366-74.

29. Coll E, Santos F, Ussetti P, Canela M, Borro JM, De La Torre M, et al. Registro Español de Trasplante Pulmonar: primer informe de resultados (2006-2010). Arch Bronconeumol. 2013;49(2):70-8.

30. Jackson AD, Goss CH. Epidemiology of CF: How registries can be used to advance our understanding of the CF population. J Cyst Fibros [Internet]. 2018;17(3):297-305. http://dx.doi.org/10.1016/j.jcf.2017.11.013. Disponible en:.

31. A Belgian study. Orphanet J Rare Dis [Internet]. 2017;12(1). Disponible en: http://dx.doi.org/10.1186/s13023-017-0694-1.

32. Mira Escolano MP, Cano Candela F, Maceda Roldán LA, Sánchez Escámez A, Seiquer de la Peña C, Serrano Pinto A, Abellán Pérez MV, Ciller Montoya P. Palomar Rodríguez JA. Prevalencia de enfermedades raras en la Región de Murcia 2015. Murcia: Consejería de Salud; 2018.

33. Consejería de Salud RM. Decreto. n. 223/2015, de 16 de septiembre, por el que se establecen los criterios de gestión y funcionamiento del Sistema de Información sobre Enfermedades Raras de la Región de Murcia [Internet]. Murciasalud.es. [citado el 16 de noviembre de 2021]. Disponible en: http://www.murciasalud.es//legislacion.php?id=331439\&idsec=79.

34. Home -. SNP - NCBI [Internet]. Nih.gov. [citado el 16 de noviembre de 2021]. Disponible en: https://www.ncbi.nlm.nih.gov/snp/.

35. ClinVar. ClinVar [Internet]. Nih.gov. [citado el 16 de noviembre de 2021]. Disponible en: https://www.ncbi.nlm.nih.gov/clinvar/.

36. De Boeck K, Zolin A. Year to year change in FEV1 in patients with cystic fibrosis and different mutation classes. J Cyst Fibros. 2017;16(2):239-45.

37. Moya-Quiles MR, Mondéjar-López P, Pastor-Vivero MD, González-Gallego I, Juan-Fita MJ, Egea-Mellado JM, et al. CFTR mutations in cystic fibrosis patients from Murcia region (southeastern Spain): implications for genetic testing. Clin Genet. 2009;76(6):577-9.

38. Alonso MJ, Heine-Suñer D, Calvo M, Rosell J, Giménez J, Ramos MD, et al. Spectrum of mutations in the CFTR gene in cystic fibrosis patients of Spanish ancestry. Ann Hum Genet. 2007;71(Pt 2):194-201.

39. Casals T, Vázquez C, Lázaro C, Girbau E, Giménez FJ, Estivill X. Cystic fibrosis in the Basque country: high frequency of mutation delta F508 in patients of Basque origin. Am J Hum Genet. 1992;50(2):404-10. 
40. Delgado Pecellín I, Pérez Ruiz E, Álvarez Ríos Al, Delgado Pecellín C, Yahyaoui Macías R, Carrasco Hernández L, et al. Results of the Andalusian cystic fibrosis neonatal screening program, 5 years after implementation. Arch Bronconeumol. 2018;54(11):551-8.

41. Duguépéroux I, De Braekeleer M, Participating Centres to the French National Cystic Fibrosis Registry. Genotype-phenotype relationship for five CFTR mutations frequently identified in western France. J Cyst Fibros. 2004;3(4):259-63.

42. Campagna G, Amato A, Majo F, Ferrari G, Quattrucci S, Padoan R, et al. Italian Cystic Fibrosis registry (ICFR). Report 2017-2018. Epidemiol Prev. 2021;45(3 Suppl 1):1-37.

43. Yiallouros PK, Matthaiou A, Anagnostopoulou P, Kouis P, Libik M, Adamidi T, et al. Demographic characteristics, clinical and laboratory features, and the distribution of pathogenic variants in the CFTR gene in the Cypriot cystic fibrosis (CF) population demonstrate the utility of a national CF patient registry. Orphanet J Rare Dis. 2021;16(1):409.

44. Bauça JM, Morell-Garcia D, Vila M, Pérez G, Heine-Suñer D, Figuerola J. Assessing the improvements in the newborn screening strategy for cystic fibrosis in the Balearic Islands. Clin Biochem. 2015;48(6):419-24.

45. Ramsey BW, Davies J, McElvaney NG, Tullis E, Bell SC, Dřevínek P, et al. A CFTR potentiator in patients with cystic fibrosis and the G551D mutation. N Engl J Med. 2011;365(18):1663-72.

46. De Boeck K, Zolin A, Cuppens H, Olesen HV, Viviani L. The relative frequency of CFTR mutation classes in European patients with cystic fibrosis. J Cyst Fibros. 2014;13(4):403-9.

47. de Gracia J, Álvarez A, Mata F, Guarner L, Vendrell M, Gadtner S, et al. Fibrosis quística del adulto: estudio de 111 pacientes. Med Clin (Barc). 2002;119(16):605-9.

48. Mehta G, Macek M Jr, Mehta A, European Registry Working Group. Cystic fibrosis across Europe: EuroCareCF analysis of demographic data from 35 countries. J Cyst Fibros. 2010;9(Suppl 2):5-21.

49. Ahmed N, Corey M, Forstner G, Zielenski J, Tsui L-C, Ellis L, et al. Molecular consequences of cystic fibrosis transmembrane regulator (CFTR) gene mutations in the exocrine pancreas. Gut. 2003;52(8):1159-64.

50. Chang EH, Zabner J. Precision genomic medicine in cystic fibrosis: Precision genomic medicine. Clin Transl Sci. 2015;8(5):60610.

51. Hubert D, Bienvenu T, Desmazes-Dufeu N, Fajac I, Lacronique J, Matran R, et al. Genotype-phenotype relationships in a cohort of adult cystic fibrosis patients. Eur Respir J. 1996;9(11):2207-14.

52. Yokoyama E, Lezana JL, Vigueras-Villaseñor RM, Rojas-Castañeda J, Saldaña-Álvarez Y, Orozco L, et al. Genotype-phenotype correlation in a sample of Mexican patients with cystic fibrosis. Rev Invest Clin. 2013;65(6):491-9.

53. Somayaji R, Stanojevic S, Tullis DE, Stephenson AL, Ratjen F, Waters V. Clinical outcomes associated with Achromobacter species infection in patients with cystic fibrosis. Ann Am Thorac Soc. 2017;14(9):1412-8.

54. Marsac C, Berdah L, Thouvenin G, Sermet-Gaudelus I, Corvol H. Achromobacter xylosoxidans airway infection is associated with lung disease severity in children with cystic fibrosis. ERJ Open Res. 2021;7(2):00076-2021.

55. Blanchard AC, Waters VJ. Microbiology of cystic fibrosis airway disease. Semin Respir Crit Care Med. 2019;40(6):727-36.

\section{Tables}

Table 1| Information sources that contribute CF patients to the SIER*. 


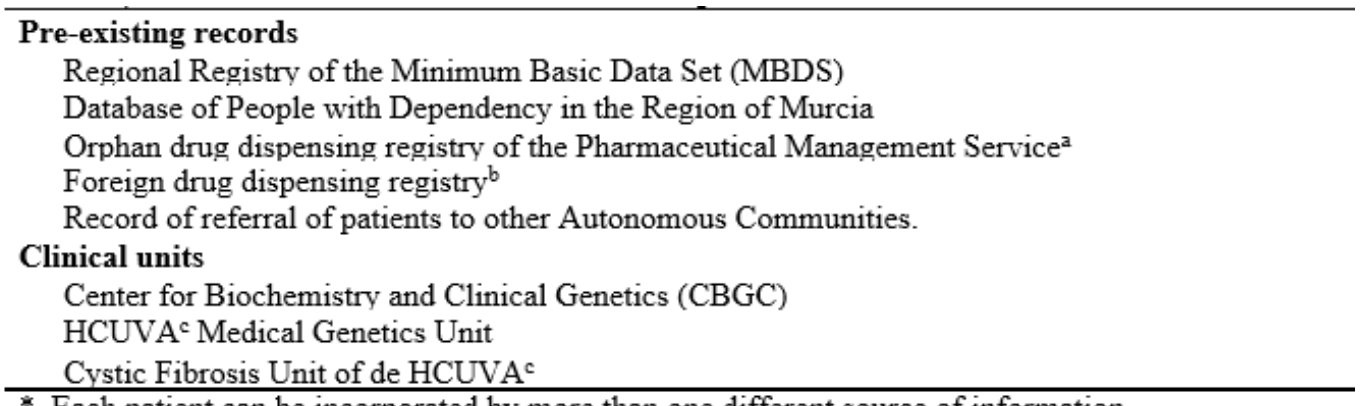

*. Each patient can be incorporated by more than one different source of information.

a. The orphan drug dispensing registry incorporated patients who had been dispensed with

Cayston $(\mathbb{B}$ and Kalydeco $\mathbb{B}$.

b. The foreign drug dispensing registry incorporated patients who had been

dispensed with Kemicetine $\mathbb{R}$ and Orkambiß).

c. HCUVA: Virgen de la Arrixaca Universitary Clinic Hospital.

Table 2| Demographic and clinical characteristics according to genotype in patients with cystic fibrosis*. 
$n^{\circ}$ patients $/ n^{\circ}$ studied (\%)

\section{Demographics characteristics}

\begin{tabular}{lllll} 
Male sex & $64 / 122(52.5)$ & $35 / 60(58.3)$ & $99 / 182(54.4)$ & 0.454 \\
\hline Age (years) ${ }^{\mathrm{a}}$. Median $(25-75)^{\mathrm{b}}$ & $15.0(7.0-28.0)$ & $28.5(11.8-42.0)$ & $19.0(8.0-33.0)$ & $<0.001$ \\
\hline Age at diagnosis $<18$ years & $114 / 117(97.4)$ & $40 / 60(66.7)$ & $154 / 177(87.0)$ & $<0.001$ \\
& & & & \\
\hline Death & $30 / 122(24.6)$ & $2 / 60(3.3)$ & $32 / 182(17.6)$ & $<0.001$ \\
\hline Lung or liver transplant & $19 / 122(15.6)$ & $4 / 60(6.7)$ & $23 / 182(12.6)$ & 0.089
\end{tabular}

\section{Clinical characteristics}

Respiratory manifestations

\begin{tabular}{|c|c|c|c|c|}
\hline $\mathrm{FEV}_{1}$ as $\%$ predicted ${ }^{\mathrm{c}}$. Mean $\pm \mathrm{SD}^{\mathrm{d}}$ & $87.1 \pm 20.5(57)$ & $94.1 \pm 22.2(40)$ & $90.0 \pm 21.4(97)$ & 0.045 \\
\hline Nasal polyposis & 18/87 (20.7) & $14 / 51(27.5)$ & $32 / 138(23.2)$ & 0.364 \\
\hline Hemoptysis & $18 / 87(20.7)$ & $12 / 51(23.5)$ & $30 / 138(21.7)$ & 0.696 \\
\hline $\mathrm{ABPA}^{\mathrm{e}}$ & $11 / 87(12.5)$ & $4 / 51(7.8)$ & 15/138 (10.9) & 0.572 \\
\hline \multicolumn{5}{|l|}{ Infection by } \\
\hline Staphylococcus aureus & $55 / 87(63.2)$ & $24 / 50(48.0)$ & 79/137 (57.7) & 0.044 \\
\hline MRSA & $10 / 87(11.5)$ & $0 / 50(0.0)$ & $10 / 137(7.3)$ & 0.013 \\
\hline Pseudomonas aeruginosa ${ }^{f}$ & $31 / 88(35.2)$ & $12 / 51(23.5)$ & $43 / 139(30.9)$ & 0.150 \\
\hline Achromobacter xylosoxidans & $14 / 87(16.1)$ & $2 / 50(4.0)$ & 16/137 (11.7) & 0.034 \\
\hline Burkholderia cepacia & $1 / 87(1.1)$ & $1 / 50(2.0)$ & $2 / 137(1.5)$ & 0.689 \\
\hline Non-tuberculous mycobacteria & $6 / 87(7.1)$ & $3 / 50(6.0)$ & $9 / 137(6.6)$ & 0.838 \\
\hline
\end{tabular}

\section{Gastrointestinal manifestations}

\begin{tabular}{l} 
Meconium ileus \\
Pancreatic insufficiency $^{\text {Pancreatitis }}{ }^{g}$ \\
Liver disease $^{\text {h }}$ \\
\hline Rectal prolapse \\
\hline Intussusception $^{\text {DIOS }}$ \\
\hline Metabolic disturbances
\end{tabular}




\begin{tabular}{llll} 
Clinically significant dehydration & $14 / 87(16.1)$ & $9 / 51(17.6)$ & $23 / 138(16.7)$ \\
\hline Bone alterations & $11 / 87(12.6)$ & $4 / 52(7.7)$ & $15 / 139(10.8)$
\end{tabular}

*. Manifestations that have been present at some point in the patient's life until December 31, 2018. The genotype information of ten patients is unknown.

a. Age on December 31st, 2018.

b. $25-75=25^{\text {th }}-75^{\text {th }}$ percentile.

c. Forced Expiratory Volume in the first second (Percentage of predicted value). The best value of the year 2018 was measured.

d. SD= Standard deviation.

e. $\mathrm{ABPA}=$ Allergic Bronchopulmonary Aspergillosis.

$\mathrm{f}$. It includes chronic colonization by Staphylococcus aureus, Pseudomonas aeruginosa and Burkholderia cepacia, and some acute infection by methicillin-resistant Staphylococcus aureus (MRSA), Achromobacter xylosoxidans and non-tuberculous mycobacteria. g. Recurrent acute or chronic pancreatitis.

h. Cirrhosis or liver disease without cirrhosis, including fatty liver.

i. DIOS= Distal Intestinal Obstruction Syndrome.

j. It includes low bone density, osteoporosis and a digital arthropathy.

Table 3| CFTR sequence variants detected in 384 alleles from 192 patients studied. 


\begin{tabular}{|c|c|c|c|c|c|}
\hline $\begin{array}{l}\text { CFTR variant } \\
\text { (Classic } \\
\text { nomenclature) }\end{array}$ & $\begin{array}{l}\text { Nucleotide/Protein } \\
\text { (Standard nomenclature) }\end{array}$ & Variant type $^{a}$ & $\begin{array}{l}\text { Molecular } \\
\text { consequence }\end{array}$ & $\begin{array}{l}\text { Clinical } \\
\text { significance }\end{array}$ & $\begin{array}{l}\text { Frequency } \\
\text { of alleles. } \\
\mathrm{N}^{\circ}(\%)\end{array}$ \\
\hline F508del & c.1521_1523delCTT/ p.Phe508del & Deletion & $\begin{array}{l}\text { Inframe } \\
\text { deletion }\end{array}$ & Pathogenic & $142(37.0)$ \\
\hline G542X & c.1624G>T/p.Gly542Ter & SNV & Nonsense & Pathogenic & $31(8.1)$ \\
\hline A1006E & c.3017C>A/p.Ala1006Glu & SNV & Missense & Pathogenic & $17(4.4)$ \\
\hline L206W & c.617T>G/p.Leu206Trp & SNV & Missense & Pathogenic & $15(3.9)$ \\
\hline $2789+5 G>A$ & c. $2657+5 \mathrm{G}>\mathrm{A} /$ * & SNV & Splicing & Pathogenic & $13(3.4)$ \\
\hline K710X & c. $2128 \mathrm{~A}>\mathrm{T} / \mathrm{p}$. Lys $710 \mathrm{Ter}$ & SNV & Nonsense & Pathogenic & $13(3.4)$ \\
\hline H609R & c. $1826 A>G / p . H i s 609 A r g$ & SNV & Missense & Pathogenic & $12(3.1)$ \\
\hline $1811+1.6 \mathrm{kbA}>\mathrm{G}$ & c. $1680-886 \mathrm{~A}>\mathrm{G} / \star \star$ & SNV & Splicing & Pathogenic & $10(2.6)$ \\
\hline R334W & c.1000C>T/p.Arg334Trp & SNV & Missense & Pathogenic & $10(2.6)$ \\
\hline N1303K & c.3909C>G/p.Asn1303Lys & SNV & Missense & Pathogenic & $9(2.3)$ \\
\hline G85E & c. $254 \mathrm{G}>\mathrm{A} / \mathrm{p} . \mathrm{Gly} 85 \mathrm{Glu}$ & SNV & Missense & Pathogenic & $8(2.1)$ \\
\hline 2869insG & c.2737_2738insG/p.Tyr913Ter & Insertion & Nonsense & Pathogenic & $7(1.8)$ \\
\hline $3849+10 \mathrm{kbC}>\mathrm{T}$ & c. $3718-2477 \mathrm{C}>\mathrm{T} / *$ & SNV & Splicing & Pathogenic & $6(1.6)$ \\
\hline $711+1 G>T$ & c. $579+1 \mathrm{G}>\mathrm{T} / *$ & SNV & Splice donor & Pathogenic & $6(1.6)$ \\
\hline 1507del & c.1516ATC[1]/ p.lle507del & Microsatellite & $\begin{array}{l}\text { Inframe } \\
\text { deletion }\end{array}$ & Pathogenic & $6(1.6)$ \\
\hline R347P & c.1040G>C/p.Arg347Pro & SNV & Missense & Pathogenic & $6(1.6)$ \\
\hline R560G & c. $1678 \mathrm{~A}>\mathrm{G} /$ p.Arg560Gly & SNV & Missense & Not provided & $4(1.0)$ \\
\hline D1152H & c.3454G>C/p.Asp1152His & SNV & Missense & Pathogenic & $3(0.8)$ \\
\hline
\end{tabular}

Table 3| (Continued).

\begin{tabular}{|c|c|c|c|c|c|}
\hline $\begin{array}{l}\text { CFTR Variant } \\
\text { (Classic } \\
\text { nomenclature) }\end{array}$ & $\begin{array}{l}\text { Nucleotide/Protein } \\
\text { (Standard nomenclature) }\end{array}$ & Variant type $\mathrm{e}^{\mathrm{a}}$ & $\begin{array}{l}\text { Molecular } \\
\text { consequence }\end{array}$ & $\begin{array}{l}\text { Clinical } \\
\text { significance }\end{array}$ & $\begin{array}{l}\text { Frequency } \\
\text { of alleles. } \\
\mathrm{N}^{\circ}(\%)\end{array}$ \\
\hline 5T-TG12 & c.[1210-34TG[12];1210-12 T[5]]/* & Deletion & $\begin{array}{l}\text { Intron } \\
\text { variant }\end{array}$ & $\begin{array}{l}\text { Conflicting } \\
\text { interpretations of } \\
\text { pathogenicity }\end{array}$ & $3(0.8)$ \\
\hline $2183 A A>G$ & c.2051_2052delinsG/ p.Lys684fs & Indel & Frameshift & Pathogenic & $2(0.5)$ \\
\hline A561E & c. $1682 \mathrm{C}>$ A/p.Ala561Glu & SNV & Missense & Pathogenic & $2(0.5)$ \\
\hline CFTRdele22,23 & c.3964-78_4242+577del/* & Deletion & $\begin{array}{l}\text { Splice } \\
\text { acceptor } \\
\text { splice donor }\end{array}$ & Pathogenic & $2(0.5)$ \\
\hline L1254X & c.3761T>G/p.Leu1254Ter & SNV & Nonsense & Pathogenic & $2(0.5)$ \\
\hline Q890X & c. $2668 \mathrm{C}>\mathrm{T} / \mathrm{p} . \mathrm{G} \ln 890 \mathrm{Ter}$ & SNV & Nonsense & Pathogenic & $2(0.5)$ \\
\hline R1162X & c. $3484 \mathrm{C}>\mathrm{T} / \mathrm{p} . \operatorname{Arg} 1162 \mathrm{Ter}$ & SNV & Nonsense & Pathogenic & $2(0.5)$ \\
\hline S549R & c. $1647 \mathrm{~T}>\mathrm{G} / \mathrm{p}$. Ser549Arg & SNV & Missense & Pathogenic & $2(0.5)$ \\
\hline 1609delCA & c.1477_1478del/p.GIn493fs & Deletion & Frameshift & Pathogenic & $1(0.3)$ \\
\hline 1677delTA & c.1545_1546del/p.Tyr515_Arg516delinsTer & Microsatellite & Nonsense & Pathogenic & $1(0.3)$ \\
\hline $1716 \mathrm{G}>\mathrm{A}$ & c. $1584 \mathrm{G}>\mathrm{A} / \mathrm{p} . \mathrm{Glu} 528=$ & SNV & Synonymous & $\begin{array}{l}\text { Conflicting } \\
\text { interpretations of }\end{array}$ & $1(0.3)$ \\
\hline
\end{tabular}


pathogenicity

\begin{tabular}{|c|c|c|c|c|c|}
\hline $1717-1 \mathrm{G}>\mathrm{A}$ & c. $1585-1 \mathrm{G}>\mathrm{A} /$ * & SNV & $\begin{array}{l}\text { Splice } \\
\text { acceptor }\end{array}$ & Pathogenic & $1(0.3)$ \\
\hline $1898+1 G>A$ & c. $1766+1 \mathrm{G}>\mathrm{A} / *$ & SNV & Splice donor & Pathogenic & $1(0.3)$ \\
\hline 2603delT & c. $2472 \mathrm{del} / \mathrm{p}$. Asn825fs & Deletion & Frameshift & Pathogenic & $1(0.3)$ \\
\hline 3195del6 & c.3067_3072del/ p.lle1023_Val1024del & Deletion & $\begin{array}{l}\text { Inframe } \\
\text { Deletion }\end{array}$ & $\begin{array}{l}\text { Pathogenic/Likely } \\
\text { pathogenic }\end{array}$ & $1(0.3)$ \\
\hline $3849+1 \mathrm{G}>\mathrm{A}$ & c. $3717 \mathrm{G}>\mathrm{A} / \mathrm{p}$. Arg1239= & SNV & synonymous & Pathogenic & $1(0.3)$ \\
\hline $621+1 \mathrm{G}>\mathrm{T}$ & c. $489+1 \mathrm{G}>\mathrm{T} /$ * & SNV & Splice donor & Pathogenic & $1(0.3)$ \\
\hline
\end{tabular}

Table 3l (Continued).

\begin{tabular}{|c|c|c|c|c|c|}
\hline $\begin{array}{l}\text { CFTR Variant } \\
\text { (Classic } \\
\text { nomenclature) }\end{array}$ & $\begin{array}{l}\text { Nucleotide/Protein } \\
\text { (Standard nomenclature) }\end{array}$ & Variant type ${ }^{a}$ & $\begin{array}{l}\text { Molecular } \\
\text { consequence }\end{array}$ & $\begin{array}{l}\text { Clinical } \\
\text { significance }\end{array}$ & $\begin{array}{l}\text { Frequency } \\
\text { of alleles. } \\
\mathrm{N}^{\circ}(\%)\end{array}$ \\
\hline $712-1 \mathrm{G}>\mathrm{T}$ & c. $580-1 \mathrm{G}>\mathrm{T} /$ * & SNV & $\begin{array}{l}\text { Splice } \\
\text { acceptor }\end{array}$ & Pathogenic & $1(0.3)$ \\
\hline A534E & c. $1601 \mathrm{C}>\mathrm{A} / \mathrm{p}$. Ala534Glu & SNV & Missense & $\begin{array}{l}\text { Uncertain } \\
\text { significance }\end{array}$ & $1(0.3)$ \\
\hline $\begin{array}{l}\text { D1270N + } \\
\text { R74W** }\end{array}$ & $\begin{array}{l}\text { c. }[220 \mathrm{C}>\mathrm{T} ; 3808 \mathrm{G}>\mathrm{A}] . \text { c. } 220 \mathrm{C}>\mathrm{T} / \\
\text { (p.Arg74Trp) }\end{array}$ & Haplotype & No data & $\begin{array}{l}\text { Uncertain } \\
\text { significance }\end{array}$ & $1(0.3)$ \\
\hline E1308X & c.3922G>T/p.Glu1308Ter & SNV & Nonsense & Likely pathogenic & $1(0.3)$ \\
\hline E585X & c. $1753 \mathrm{G}>$ A/p.Glu585Ter & SNV & Nonsense & Pathogenic & $1(0.3)$ \\
\hline $\begin{array}{l}\text { G451V + } \\
\text { G253R }\end{array}$ & $\begin{array}{l}\text { c. } 1352 \mathrm{G}>\mathrm{T} / \text { p.Gly451Val. } \\
\text { c.757G>A/p.Gly253Arg }\end{array}$ & Haplotype & No data & $\begin{array}{l}\text { Uncertain } \\
\text { significance }\end{array}$ & $1(0.3)$ \\
\hline G85V & c.254G>T/p.Gly85Val & SNV & Missense & Pathogenic & $1(0.3)$ \\
\hline L15P & c. $44 T>$ C/p.Leu15Pro & SNV & Missense & Pathogenic & $1(0.3)$ \\
\hline R1066C & c.3196C>T/p.Arg1066Cys & SNV & Missense & Pathogenic & $1(0.3)$ \\
\hline R1158X & c.3472C>T/p.Arg1158Ter & SNV & Nonsense & Pathogenic & $1(0.3)$ \\
\hline $\mathrm{R} 117 \mathrm{H}$ & c. $350 \mathrm{G}>\mathrm{A} / \mathrm{p}$. Arg $117 \mathrm{His}$ & SNV & Missense & Pathogenic & $1(0.3)$ \\
\hline V562I & c. $1684 \mathrm{G}>\mathrm{C} / \mathrm{p}$. Val562lle & SNV & Missense & $\begin{array}{l}\text { Conflicting } \\
\text { interpretations of } \\
\text { pathogenicity }\end{array}$ & $1(0.3)$ \\
\hline W1089X & c.3266G>A/p.Trp1089Ter & SNV & Nonsense & Pathogenic & $1(0.3)$ \\
\hline W1282X & c.3846G>A/p.Trp1282Ter & SNV & Nonsense & Pathogenic & $1(0.3)$ \\
\hline W202X & c. $606 \mathrm{G}>$ A, p.Trp202Ter & SNV & Nonsense & Not provided & $1(0.3)$ \\
\hline Unknown data & - & - & - & - & $25(6.5)$ \\
\hline
\end{tabular}

${ }^{(*)}$ No protein name. $\left.{ }^{\star \star}\right)$ Complex alleles. a SNV: Single nucleotide variant

Table 4 Multivariate analysis for the clinical manifestations of people with cystic fibrosis and their genotype*. 


\begin{tabular}{|c|c|c|c|c|c|c|}
\hline \multicolumn{7}{|l|}{ Genotype } \\
\hline \multirow[t]{2}{*}{ Variables } & \multicolumn{3}{|c|}{ Unadjusted } & \multicolumn{3}{|c|}{ Adjusted } \\
\hline & OR & $95 \% \mathrm{Cl}$ & P-value & OR & $95 \% \mathrm{Cl}$ & P-value \\
\hline$\% \mathrm{FEV}_{1} \star *$ & 1.8 & $0.73-3.84$ & 0.226 & 3.4 & $1.10-10.83$ & 0.034 \\
\hline S. Aureus infection & 1.9 & $0.92-3.77$ & 0.084 & 1.4 & $0.61-3.11$ & 0.447 \\
\hline MRSA infection & 3.2 & $0.70-14.86$ & 0.136 & 3.6 & $0.58-23.44$ & 0.173 \\
\hline Pseudomonas aeruginosa infection & 1.8 & $0.81-3.84$ & 0.155 & 4.2 & $1.29-13.81$ & 0.017 \\
\hline Achromobacter xylosoxidans infection & 4.5 & $0.99-20.87$ & 0.052 & 7.1 & $1.08-47.15$ & 0.042 \\
\hline Meconium ileus & 4.7 & $1.19-18.64$ & 0.028 & 3.6 & $0.81-16.13$ & 0.093 \\
\hline Pancreatic insufficiency & 17.2 & $7.57-39.01$ & $<0.001$ & 21.8 & $7.94-59.91$ & $<0.001$ \\
\hline Liver disease & 3.7 & $0.98-14.30$ & 0.053 & 2.4 & $0.54-11.13$ & 0.248 \\
\hline CF-related diabetes & 3.5 & $3.52-13.51$ & 0.067 & 3.5 & $0.82-14.96$ & 0.086 \\
\hline \multicolumn{7}{|c|}{ *. Results for high-risk genotype using low risk genotype as a reference. } \\
\hline \multicolumn{7}{|l|}{$\star \star$. Dichotomized in $\leq 90 \%$ and $>90 \%$. } \\
\hline Adjusted m & 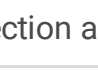 & on & 20 & & & \\
\hline
\end{tabular}

